DOI: https://doi.org/10.46296/rc.v4i7.0024

\title{
Consideraciones teóricas sobre la gestión de las Microfinanzas con un enfoque de Finanzas Populares y Solidarias
}

\section{Theoretical considerations about the Microfinances management with a Popular and Solidarity Finances Approach}

\author{
Autora: Verduga-Pino Alexandra \\ Universidad Técnica de Manabí (UTM). Portoviejo, Ecuador. \\ https://orcid.org/0000-0003-4864-0499 \\ alexandra.verduga@utm.edu.ec
}

\begin{abstract}
RESUMEN
La necesidad de impulsar el cambio de las relaciones de desigualdad, exclusión e injusticia imperantes en iniciativas inclusivas y en alternativas que favorezcan el desarrollo de los territorios en Ecuador condujo a la realización de una investigación en la cual se demuestra que la transformación de las Microfinanzas en Finanzas Populares y Solidarias constituye la vía idónea para lograrlo. Este artículo se propone realizar la valoración de las Microfinanzas desde su naturaleza socio económica y su participación en el contexto del sector financiero ecuatoriano. Además, abordar el sistema novedoso de la constitución del Ecuador: la Economía Popular y Solidaria y, en especial, las Finanzas Populares y Solidarias. Las consideraciones teóricas derivadas del análisis realizado sustentan la gestión de las Microfinanzas con un enfoque de Finanzas Populares y Solidarias.
\end{abstract}

Palabras claves: Microfinanzas, Finanzas Populares y Solidarias, sector financiero, Economía Popular y Solidaria.

\section{ABSTRACT}

The need to accelerate the change of inequality relations, exclusion and injustice into inclusive initiatives and alternatives favoring the development of territories in Ecuador led to an investigation which demonstrates that the transformation of Microfinances into Popular and Solidarity Finances constitute the best via to attain that purpose. This paper aims at presenting the assessment of Microfinances since their socio-economic nature and their role in the Ecuadorian financial sector. Moreover, the outstanding Ecuadorian Constitution System: The Popular and Solidarity Economy, particularly, the Popular and Solidarity Finances is considered. The Microfinances management with a Popular and Solidarity Finances Approach is based on the theoretical considerations derived from the analysis carried out.

Keywords: Microfinances, Popular and Solidarity Finances, financial sector, Popular and Solidarity Economy

Información del manuscrito:

Fecha de recepción: 26 de octubre de 2020.

Fecha de aceptación: 04 de enero de 2021.

Fecha de publicación: 11 de enero de 2021. 


\section{INTRODUCCIÓN}

Los problemas que enfrenta el ser humano en la actualidad y las crisis por las que atraviesa han alcanzado niveles impresionantes, incidiendo de forma dramática en aquellos sectores vulnerables y excluidos, enfrentados a un escenario de desigualdad, que los coloca en el grupo de los pobres y marginados.

Las diferentes formas de organización y producción de los sectores populares que no funcionan con la lógica de acumulación del capital adquieren importancia, y hacen que surjan mecanismos alternativos a la banca comercial tradicional, lo que favorece la construcción de un nuevo modelo de desarrollo social y económico concatenado a un sistema financiero inclusivo, dentro del cual las Finanzas Populares y Solidarias alcanzan su mayor expresión.

El objetivo de este artículo es valorar las microfinanzas desde su naturaleza socio económica y su participación en el contexto del sector financiero ecuatoriano, así como abordar el sistema novedoso de la constitución del Ecuador: la Economía Popular y Solidaria y, en especial, las Finanzas Populares y Solidarias. Para ello se emplearon métodos del nivel teórico tales como el histórico-lógico, analítico-sintético, inductivo-deductivo que permitieron llegar a consideraciones teóricas para sustentar la gestión de las Microfinanzas con un enfoque de Finanzas Populares y Solidarias como resultado de la investigación realizada.

\section{MARCO TEÓRICO}

Desde hace mucho tiempo, se reconocen en todo el mundo iniciativas de préstamo de dinero surgidas ante la necesidad de encontrar opciones para combatir la pobreza. Estas iniciativas sociales, a través de las cuales prestar dinero en condiciones favorables a quienes son marginados de la banca tradicional, y de entre estos, a los más pobres, condujeron a lo que hoy se denomina microcrédito.

En Ecuador, a partir del Consenso de Washington cuyas medidas se orientaron a la liberalización de los mercados, la disciplina fiscal, la privatización y la 
Revista Científica Arbitrada de Investigación en Comunicación, Marketing y Empresa REICOMUNICAR. Vol. 4, Núm. 7 (ene - jun 2021) ISSN: 2737-6354.

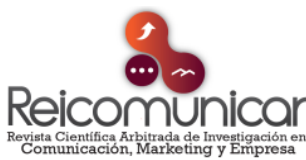

Consideraciones teóricas sobre la gestión de las Microfinanzas con un enfoque de Finanzas

Populares y Solidarias

apertura de la inversión extranjera, los ajustes estructurales impulsados por las agencias multilaterales, la reducción del estado y su retiro de la intervención en la economía, se creó una crisis financiera que rompió por completo con todo el sistema financiero ecuatoriano y provocó el llamado "feriado bancario" (apropiación indebida del dinero de los ecuatorianos por los bancos). Ello implicó la pérdida de los fondos del país, la dolarización de la economía y la creación espontánea en las comunidades, de formas populares encaminadas a captar el ahorro y suministrar dinero a través del microcrédito como alternativa financiera.

El microcrédito se define como un "programa de concesión de pequeños créditos a los más necesitados para que puedan poner en marcha pequeños negocios que generen ingresos con los que logren mejorar su nivel de vida y el de sus familias" (OIT, 2005).

En la literatura consultada, diferentes autores estudiados (Yunus, 2008; Coraggio, 2011; Auquilla \& Del Castillo, 2013) coinciden en que el microcrédito se refiere a pequeños préstamos realizados a personas pobres, los cuales se pagan de forma fraccionada.

Muhammad Yunus, conocido como el padre del microcrédito, encontró en este una nueva forma de concebir la lucha contra la pobreza y la exclusión financiera de los más pobres. Según Yunus (2006 citado por Garayalde, 2014), a través del microcrédito se demuestra que las personas excluidas del sistema bancario están igual de dotadas para emprender, gestionar sus propios negocios y generar recursos.

Las Naciones Unidas consideraron el microcrédito como un instrumento capital para erradicar la pobreza de cara a los objetivos del milenio, al centrarse en actividades del sector informal, movilizar el microahorro, combatir las prácticas de usura, permitir una mayor igualdad de género en el acceso a la actividad económica y facilitar el flujo de las remesas, entre otros (Flores \& San Martin, 2017).

El microcrédito constituye una herramienta financiera que revolucionó el mundo de las finanzas entre las diferentes capas de la población más desfavorecida, concediendo préstamos de pequeñas cantidades de dinero con garantías mutuas y solidarias a personas que no son aceptados como prestatarios por la 
banca tradicional, ante la imposibilidad de contar con las garantías y los requisitos que esta exige.

Sin embargo, de acuerdo con lo expresado por varios autores (Paucar, 2013; Hernández, 2014) al microcrédito se le atribuyen determinadas críticas entre ellas: la escasez de fondos, el impedimento para lograr el acceso al mismo por todas las personas, las altas tasas de interés, la provisión de servicios limitados, la informalidad, entre otras.

Todo lo antes planteado revela una situación que perjudica esencialmente a las personas que no cuentan con suficientes recursos y que solicitan pequeños préstamos de subsistencia. Estos préstamos no implican que su ingreso prestatario varíe sustancialmente, incluso en algunos casos, llegan a reducir sus oportunidades de ingresos debido a que aumenta su nivel de endeudamiento.

Entre los factores que limitan los servicios financieros del microcrédito al sector pobre se encuentran: pequeños activos en calidad y cantidad; altos costos de operación; problemas de reembolso inherente a la falta de activos o al riesgo en la utilización de los préstamos para el consumo sin fuentes de ingresos fijas; falta de capacidad prestamista de primer piso sólido y competente, que constituye uno de los principales obstáculos para extender los servicios financieros; propiedad y estructura de gobierno, así como supervisión de la gestión, como factores críticos para la provisión eficaz de servicios financieros.

Se puede reafirmar entonces, que el sistema financiero convencional no ha sido el adecuado para la promoción de un desarrollo local que favorezca a los sectores vulnerables de la sociedad, pues son sistemas financieros excluyentes, que tampoco respaldan experiencias alternativas de organización económica.

Uno de los principales problemas que enfrentan los emprendedores de los territorios es la escasez de crédito y el no contar con instituciones financieras que ofrezcan suficientes productos para atender sus necesidades de financiamiento, lo que abre paso a las Microfinanzas.

Las Microfinanzas, iniciadas con operaciones de microcrédito, se definen como "la provisión de servicios financieros para personas en situación de pobreza, 
Revista Científica Arbitrada de Investigación en Comunicación, Marketing y Empresa REICOMUNICAR. Vol. 4, Núm. 7 (ene - jun 2021) ISSN: 2737-6354.

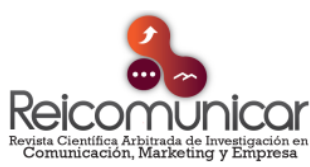

Consideraciones teóricas sobre la gestión de las Microfinanzas con un enfoque de Finanzas Populares y Solidarias

microempresas o clientes de bajos ingresos, incluyendo consumidores y autoempleados" (Ledgerwood, 2000, p. 2).

En sentido general, se refieren a servicios financieros tales como préstamos, ahorros y seguros dirigidos a personas que no tienen acceso a los sistemas bancarios tradicionales, dada su desfavorable condición socioeconómica. Consisten en otorgar créditos e incentivar el ahorro en las personas excluidas del sistema tradicional y se orientan a un amplio rango de necesidades financieras de personas en situación de pobreza y, por tanto, abarcan a los microcréditos, pero constituyen un concepto más amplio.

Las Microfinanzas brindan a un masivo número de prestatarios, fondos para emprendimientos a pequeña escala y, además, involucran operaciones muy homogéneas entre sí. Por otra parte, evitan que las personas recurran a créditos ilegales o usureros, donde las tasas de interés son elevadas.

A partir del siglo XIX, los antecedentes más visibles de las Microfinanzas en el mundo en desarrollo, donde abundan las economías informales, se inician con actividades de microcrédito y asociaciones de ahorro y crédito en África, conocidas como ROSCA por sus siglas en inglés (asociaciones rotatorias de ahorro y crédito).

En este mismo siglo, y de manera simultánea, las experiencias de Cajas de Ahorros y préstamos se inician en Alemania por Friedrich Wilhelm Raiffeisen, lo que dio lugar a la creación de un gran número de bancos mutualistas en toda Europa; estos tuvieron como fin promover el ahorro popular y desarrollar el pequeño crédito entre los campesinos, artesanos y comerciantes, de manera que se les pudiera proteger de prestamistas inescrupulosos y usureros.

Dentro de la Red Europea de Microfinanzas, que cuenta con 36 miembros en 16 países (Cárdenas, Hirsch, \& Lara Gómez, 2015) se encuentra España, que tiene la finalidad de construir un sector financiero abierto a todos. Según Maldonado, Aráuz, \& Pinos (2017), esto representa un buen indicio de lo que se proyecta en este ámbito, estableciendo las cajas de ahorros, entidades que han apostado con mayor decisión por este instrumento financiero. 
Como plantean Carballo et al (2016), fieles a su vocación social, y vinculadas con sus orígenes fundacionales de lucha contra la usura y contra la exclusión financiera de los más desfavorecidos, las cajas de ahorros han puesto en marcha diferentes sistemas microfinancieras, aunque están evolucionando de una forma dispersa y poco sistemática, de manera que cada entidad los gestiona de una manera particular.

A partir de los años 90, los programas de Microfinanzas han jugado un papel importante en su pretensión por lograr el desarrollo de los territorios y en la lucha contra la pobreza.

Las Microfinanzas posibilitan el acceso a servicios financieros de todo tipo (crédito, ahorro, medios de pago), lo que tributa a la construcción de sistemas financieros incluyentes y alternativos, que influyen de manera positiva en el desarrollo del territorio. A partir de su alcance en todo el mundo y de los cambios que han producido en los sistemas financieros, es preciso analizar qué políticas podrían implementarse de manera que dichos cambios tengan una influencia positiva, tanto en el desarrollo de las regiones, como en la equidad y la lucha contra la pobreza.

Entre los principios clave de las Microfinanzas formulados y aprobados por el Grupo Consultivo para Ayudar a los Pobres y sus 33 miembros cooperantes, y adicionalmente aprobados por el Grupo de los Ocho durante la Cumbre del 2004 se relacionan los siguientes: las personas de escasos recursos necesitan una variedad de servicios financieros, no sólo préstamos; las Microfinanzas representan una herramienta poderosa en la lucha contra la pobreza; se refieren a la creación de sistemas financieros que atiendan las necesidades de las personas pobres y podrán alcanzar su máximo potencial, si son integradas al sistema financiero ya establecido de un país; las Microfinanzas pueden y deben ser sostenibles, si se espera abarcar a un gran número de personas pobres; requieren la construcción de instituciones financieras locales y permanentes que puedan atraer depósitos de remesas familiares y ganancias de los emprendimientos, reciclarlos en forma de préstamos, y ofrecer otros servicios financieros. 
Revista Científica Arbitrada de Investigación en Comunicación, Marketing y Empresa REICOMUNICAR. Vol. 4, Núm. 7 (ene - jun 2021) ISSN: 2737-6354.

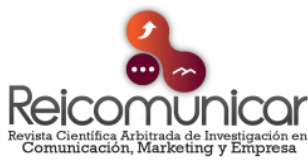

Consideraciones teóricas sobre la gestión de las Microfinanzas con un enfoque de Finanzas

Populares y Solidarias

No obstante, debe tenerse en cuenta que el microcrédito por sí solo no elimina la pobreza, otros tipos de ayuda son ideales para aquellas personas tan pobres que no tienen ingresos ni medios de repago; los techos a las tasas de interés pueden perjudicar el acceso de las personas pobres a créditos; la fijación de tasas de interés máximas impide que las instituciones microfinancieras cubran sus costos, y por ello, hace que se corte la oferta de crédito para las personas pobres.

En este sentido, el papel del gobierno debe ser el de facilitador, no de proveedor directo de servicios y también, puede establecer un marco político de apoyo; los fondos de los cooperantes deben complementar, en vez de competir con el capital del sector privado y los subsidios que ofrecen deben ser una ayuda temporal de arranque y estar diseñados a apoyar a una institución hasta que ésta pueda explotar fuentes de fondos privadas.

Actualmente, las Microfinanzas siguen cumpliendo su rol como entidades proveedoras de crédito a pequeñas iniciativas de emprendimientos en la región donde actúan. Sin embargo, existen dudas en cuanto al impacto que estas han logrado y a la forma en que los objetivos sociales y económicos se armonizan entre sí. En este sentido, se observan diferentes posiciones.

Según algunos autores (Udry y Aryeetey, 2010; Banerjee et al, 2009) el impacto de las Microfinanzas se evidencia en la mejora de las condiciones de vida de sus usuarios; se trata no sólo de medir los aspectos financieros, sino también los producidos en la vida de las personas, así como en su territorio o región.

Aquellos que se han preocupado por medir el impacto real de los programas de Microfinanzas sobre sus usuarios (van Rooyen, Stewart, De Wet, 2012) coinciden en que estas han abierto un camino, que desde otra perspectiva se pudiese convertir, junto con otras políticas, en un factor de desarrollo y reducción de la pobreza, desde una oferta financiera creativa en el territorio para cubrir la demanda local generada, mayoritariamente, por las iniciativas de emprendimientos de la zona.

Abarcar las Microfinanzas desde una política de inserción productiva implica usar el sistema financiero como instrumento de ampliación de posibilidades de ahorro y consumo, que responda a las diversas necesidades de financiamiento. Pérez 
\& Titelman (2018) consideran que la falta de acceso a las finanzas es un mecanismo crítico para perpetuar la desigualdad del ingreso y mantener un bajo crecimiento, opinión que es avalada por estudios recientes acerca de las Microfinanzas realizados por el Banco Mundial.

Al valorar críticamente estas posiciones que absolutizan el rol del financiamiento, se corrobora que la participación, la gestión microfinanciera, el fortalecimiento de las comunidades y las formas productivas asociativas constituyen factores determinantes, junto a las políticas públicas para el fomento de un desarrollo sostenible, desde el punto de vista económico y social a largo plazo.

Duvendack et al (2011) señalan que la mayoría de los estudios de impacto de las Microfinanzas realizados en Asia han obtenido resultados interesantes para el análisis de los mercados financieros. Además, han tenido otras consecuencias financieras como el incremento del ahorro o la acumulación de activos como pequeña maquinaria e impactos no financieros en la salud, la seguridad alimenticia, la nutrición, la educación, la creación de empleo, la situación de la mujer y la cohesión social.

La idea que subyace en todos estos estudios es que, al proporcionar servicios financieros a los pobres, estos administran su dinero de forma diferente, invirtiendo, comprando activos productivos, mejorando su rendimiento personal, su auto estima y elevando los niveles de confianza.

Otros estudios realizados por Copestake, Bhalotra y Johnson (2001) manifiestan impactos positivos de las Microfinanzas para los pobres, no así para los más pobres; además se señala que las Microfinanzas han mejorado sus ingresos, pero no lo suficiente.

Con respecto a la situación de la mujer, se considera que parece haber mejorado, pero aún subsisten grandes desigualdades (Husain, Mukherjee y Dutta, 2014).

De acuerdo con Karnani (2007) el dinero dedicado a las Microfinanzas podría ser más efectivo con otro tipo de intervenciones, sobre todo, si se combina con programas de salud o educación general. 
Revista Científica Arbitrada de Investigación en Comunicación, Marketing y Empresa REICOMUNICAR. Vol. 4, Núm. 7 (ene - jun 2021) ISSN: 2737-6354.

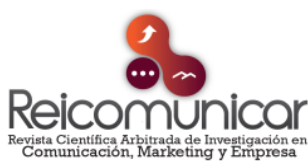

Consideraciones teóricas sobre la gestión de las Microfinanzas con un enfoque de Finanzas Populares y Solidarias

Por otra parte, los estudios referidos al África (Ashraf, Gine y Karlan, 2008), también demuestran que las Microfinanzas disminuyen la pobreza y mejoran la calidad de vida de los clientes

En cambio, Nanor (2008) indica que cuanto más tiempo un cliente utilice las Microfinanzas, peores resultados obtienen en su actividad, lo que muestra que el solo hecho de recibir financiamiento no constituye garantía de un buen desempeño empresarial.

Desde la experiencia internacional, la industria de las Microfinanzas en América Latina atraviesa una acelerada transformación, por ejemplo: si antes estaba compuesta por organizaciones no gubernamentales (ONGs) que financiaban donativos y no tenían fines de lucro, hoy esta industria comprende una amplia gama de instituciones financieras que se caracterizan por una creciente inquietud por la eficiencia y la rentabilidad de sus operaciones. En opinión de Morduch (2000), esta evolución ha generado un importante debate entre organismos internacionales y administradores de microfinancieras.

La actividad microfinanciera para el caso de América Latina, en los últimos 20 años ha sido interesante, pues el crecimiento de las mismas ha sido explosivo, pasando de un pequeño experimento de desarrollo a un negocio de millones de dólares, se ha logrado bancarizar a millones de personas y a miles de empresas (CEPAL ECUADOR, 2017). Sin embargo, existen muy pocos estudios que apunten a medir el acceso propiamente dicho, es decir, a relacionar el número de clientes con el total de empresas o población.

La limitación crucial de las Microfinanzas es la insuficiencia de instituciones que las respalden, por ello es relevante destacar que funcionan de forma diferente en las distintas regiones. El mayor desafío de las Microfinanzas, indica la CEPAL, es equilibrar una cobertura adecuada, la suficiencia en las prestaciones y la sostenibilidad financiera (CEPAL, 2018). Sin embargo, se ha observado en algunos de los países más importantes del área una reducción del papel del Estado y la elevación de los niveles de desigualdad y exclusión social, por lo que los desafíos de las Microfinanzas no dependen solo de las trasformaciones que ellas encierran en sí misma; pues los cambios del poder político y las incertidumbres que representan constituyen una fuerte amenaza para el 
cumplimiento de sus objetivos, por lo que se requiere la participación de más actores que influyan en el territorio como los Gobiernos Autónomos Descentralizados, las universidades, las ONGs, entre otros.

Si bien las Microfinanzas han abierto un camino hacia el desarrollo de los territorios y han posibilitado la inclusión financiera de los sectores vulnerables de la sociedad, los cuales han sido excluidos por la banca tradicional debido a su precaria condición socio-económica, aun no resuelven del todo la situación de este sector desfavorecido, por lo que se precisa de otras alternativas de organización del sistema financiero que permitan mejorar las condiciones sociales y económicas, y potenciar el desarrollo de los territorios. Además, se requiere considerar una mejor manera de que la oferta de servicios financieros pueda contribuir al desarrollo económico: el fomento y fortalecimiento de las finanzas populares que armonicen criterios de rentabilidad económica y rentabilidad social.

\section{Las microfinanzas en el contexto del sector financiero ecuatoriano}

Las Microfinanzas se formalizan en el Sistema Financiero del Ecuador a partir de junio de 2002, con la emisión de la normativa contenida en la Resolución No. JB-2002-457 del 10 de junio, efectuada por la Junta Bancaria. La primera información financiera de las Microfinanzas aparece en los balances de la Superintendencia de Bancos en el mes de julio de 2002. Se les define en el Ecuador, como organizaciones que tienen como objetivo fundamental hacer que los pobres que trabajan por cuenta propia, especialmente mujeres, tengan acceso a servicios financieros confiables, para lo cual han intentado transformar actividades financieras desde la banca privada.

De acuerdo con lo estipulado en el numeral 1.4 de la Resolución No. 209-2016F del 12 de febrero de 2016 de la Junta de Política y Regulación Monetaria y Financiera, se define al microcrédito de la siguiente manera:

Es el otorgado a una persona natural o jurídica con un nivel de ventas anuales inferior o igual a cien mil dólares de los Estados Unidos de América (US\$ 100.000,00), a un grupo de prestatarios con garantía solidaria, destinado a financiar actividades de producción y/o comercialización en pequeña escala, cuya fuente principal de pago constituye el producto de las 
Revista Científica Arbitrada de Investigación en Comunicación, Marketing y Empresa REICOMUNICAR. Vol. 4, Núm. 7 (ene - jun 2021) ISSN: 2737-6354.

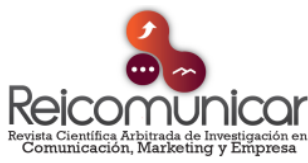

Consideraciones teóricas sobre la gestión de las Microfinanzas con un enfoque de Finanzas Populares y Solidarias

ventas 0 ingresos generados por dichas actividades, verificados adecuadamente por la entidad del sistema financiero público o privado (SBS, Ecuador 2002).

La Superintendencia de Bancos y Seguros (SBS) divide a los microcréditos en:

Microcrédito minorista: operaciones otorgadas a solicitantes de crédito cuyo saldo adeudado en microcréditos a la entidad financiera, sea menor o igual a mil dólares de los Estados Unidos de América (US\$1.000,00), incluyendo el monto de la operación solicitada.

Microcrédito de acumulación simple: operaciones otorgadas a solicitantes, cuyo saldo adeudado en microcréditos a la entidad financiera, sea superior a mil dólares de los Estados Unidos de América (US\$1.000,00) y hasta diez mil dólares de los Estados Unidos de América (USD\$10.000,00), incluyendo el monto de la operación solicitada.

Microcrédito de acumulación ampliada: operaciones otorgadas a solicitantes de crédito cuyo saldo adeudado en microcréditos a la entidad financiera, sea superior a diez mil dólares de los Estados Unidos de América (US\$10.000,00), incluyendo el monto de la operación solicitada.

Mediante Resolución No.391-2017-F del 31 de julio de 2017, la Junta de Política y Regulación Monetaria y Financiera dispone que para el año 2017, el banco público Banecuador deberá canalizar sus recursos, principalmente a los segmentos de microcrédito y vivienda de interés público. De igual forma señala que la Corporación Nacional De Finanzas Populares y Solidarias (CONAFIPS), dentro de la colocación de segundo piso, orientará su programa de crédito a los segmentos: comercial prioritario, microcrédito y vivienda de interés público (JPME, 2017).

El 26 de enero de 2018 la Junta de Política y Regulación Monetaria y Financiera con el afán de apoyar financieramente a los microempresarios emitió la resolución No.437-2018-F, a través de la cual fijó las tasas de interés activas efectivas máximas para el microcrédito en: Microcrédito Minorista: 28,50\%; Microcrédito de Acumulación Simple: 25,50\% y Microcrédito de Acumulación Ampliada: $23,50 \%$. 
En la citada resolución se estipula que las tasas detalladas aplicarán para el sector financiero público, el sector financiero privado, las mutualistas y entidades del segmento 1 del sector financiero popular y solidario; mientras que, para las demás entidades se mantendrán las tasas de microcréditos, los porcentajes que entraron en vigencia desde el 1 de febrero de 2018 (JPM-E, 2018).

- Microcrédito Minorista: 30,50\%

- Microcrédito de Acumulación Simple: 27,50\%

- Microcrédito de Acumulación Ampliada: 25,50\%

De las cifras expuestas se determina que se han bajado en 2 puntos porcentuales las tasas de interés máximas efectivas de los microcréditos. Esta disminución, si bien es favorable para los pequeños emprendedores, podría afectar los ingresos y, por ende, los resultados de las entidades que otorgan este tipo de créditos, especialmente, aquellas cuya política crediticia es el cobro de tasas de interés en sus niveles máximos. En el caso contrario, esta disminución no tendría efecto negativo en los resultados de las entidades financieras que, dentro de su política crediticia en el afán de ser competitivos y por lo mismo captar un mayor número de clientes, cobran tasas inferiores a los techos permitidos.

En el ámbito de las Microfinanzas desde el contexto del sector financiero ecuatoriano, en lo respecta a las demandas de crédito por emprendimientos, se hace referencia a los datos contenidos en el Reporte del Monitoreo del Emprendimiento Global, los cuales provienen de una encuesta realizada a 2.000 adultos (mayores de 18 años), complementado con encuestas a un mínimo de 36 expertos nacionales (emprendedores, servidores públicos, académicos, y profesionales) de los cuales se recogen sus opiniones acerca de los factores que tienen un determinado impacto sobre el ecosistema emprendedor en cada economía (GEM-E, 2016).

El monto promedio requerido para iniciar un emprendimiento en Ecuador es de USD 2.000, según señala el GEM 2016 en base a los datos suministrados por la Alianza para el Emprendimiento y la Innovación (AEI, 2016). Estos emprendimientos pertenecen a la categoría de economías de eficiencia dentro 
Revista Científica Arbitrada de Investigación en Comunicación, Marketing y Empresa REICOMUNICAR. Vol. 4, Núm. 7 (ene - jun 2021) ISSN: 2737-6354.

Consideraciones teóricas sobre la gestión de las Microfinanzas con un enfoque de Finanzas Populares y Solidarias

de la clasificación de tres fases de desarrollo económico, economías de factores, economías de eficiencia y economías de innovación.

De acuerdo con la evaluación del entorno para el 2016 se determina que, en lo referente al Ecosistema Emprendedor se incluyen las percepciones de expertos para nueve condiciones marco emprendedoras como son: apoyo financiero; políticas gubernamentales (políticas generales y regulación); programas gubernamentales; educación y formación en emprendimiento; transferencia de conocimiento $(\mathrm{I}+\mathrm{D})$; infraestructura comercial y legal; dinamismo interno del mercado y regulación de entrada, infraestructura física, y normas sociales y culturales.

Los aspectos fundamentales que limitan el impulso de los emprendimientos que mayoritariamente corresponden a las Microfinanzas, son la falta de apoyo financiero $(2,86$ de puntaje) y de políticas gubernamentales de regulación $(2,68)$, ya que estos factores son los más bajos en comparación con Colombia $(3,63$ y $3,60)$, Perú $(3,83$ y 3,14), Chile $(3,53$ y 4,74), de la Región (América Latina y el Caribe) $(3,42$ y 3,31$)$ y de las Economías de Eficiencia $(4,07$ y 3,67, respectivamente) a la cual pertenece Ecuador (BCE,2016).

Adicionalmente, los factores citados fueron los más desfavorables en promedio entre los años 2010 y 2015, pues registraron los puntajes más bajos de los nueve evaluados, con cifras de 3,95 en el factor referido a la falta de apoyo financiero y de 2,28 en cuanto a las políticas gubernamentales de regulación.

El financiamiento de los emprendimientos, según lo describe el GEM 2016 (GEM-E 2016), proviene mayoritariamente de recursos propios (fuente interna) y de fuentes externas como: los Bancos (47\%), los denominados inversionistas informales con una participación del $30 \%$ y el $4 \%$ de recursos del Gobierno.

Por otra parte, el 3,2\% del financiamiento los emprendedores lo obtienen de inversionistas privados (capital de riesgo o venture capital) y mediante crowdfundig obtienen el $1,7 \%$ de los recursos. También, otros actores que financian emprendimientos son el "Capital semilla", proyecto generado a través del Ministerio de Industrias y Productividad del Ecuador que brinda financiamiento a emprendedores innovadores. Esta es una oferta que gobierno ecuatoriano pone a disposición del sector productivo. 
Otro mecanismo de financiamiento con que cuentan los emprendedores, en este caso los emprendedores de la Economía Popular y Solidaria son los recursos de la CONAFIPS, fondos que se canalizan por medio de las Organizaciones del Sector Financiero Popular y Solidario (OSFPS) que hasta agosto de 2017 totalizaron en el país 151 entidades, dentro de las cuales constan 137 Cooperativas de Ahorro y Crédito, 5 Fundaciones, 3 Cajas Solidarias, 1 Mutualista y 5 entidades diversas.

\section{Economía Popular y Solidaria/Finanzas Populares y Solidarias: marco institucional}

La Economía Popular y Solidaria (EPS) tiene como antecedente a la Economía Social surgida en el siglo XIX en Europa. En su sentido más amplio, la Economía Social es el conjunto de intereses de la sociedad, pero en estudios realizados por diferentes autores (Spear, 2001; López, 2003; CEPES, 2012 citados en Auquilla, 2014) se le concibe como un conjunto de formas que se instituyen en asociaciones, bancos comunales, pequeñas cajas de ahorro, fundaciones, mutualistas y cooperativas, en las que prevalece el interés general sobre el particular, en las que la toma de decisiones se realiza equitativa y participativamente y en la que predomina el trabajo por sobre el capital; esta economía genera valor agregado y puestos de trabajo y su dinámica es diferente a la del sector público y a la del sector capitalista.

Por su parte, la Economía Popular ha sido de interés para diversos investigadores. Según Sarría (2010) la Economía Popular es:

El conjunto de actividades económicas y prácticas sociales desarrolladas por los sectores populares con miras a garantizar, a través de la utilización de su propia fuerza de trabajo y de los recursos disponibles, la satisfacción de las necesidades básicas, tanto materiales como inmateriales (p. 173).

La Economía Solidaria surgida en América Latina en la década del 90 se define como "el sistema socio-económico, cultural y ambiental desarrollado de forma individual o colectiva a través de prácticas solidarias, participativas, humanistas y sin ánimo de lucro para el desarrollo integral del ser humano como fin de la economía" (Askunze, 2007, p. 2). 
Revista Científica Arbitrada de Investigación en Comunicación, Marketing y Empresa REICOMUNICAR. Vol. 4, Núm. 7 (ene - jun 2021) ISSN: 2737-6354.

Consideraciones teóricas sobre la gestión de las Microfinanzas con un enfoque de Finanzas Populares y Solidarias

En el contexto ecuatoriano se entiende por Economía Popular y Solidaria al:

Conjunto de formas y prácticas económicas, individuales o colectivas, auto gestionadas por sus propietarios que, en el caso de las colectivas, tienen simultáneamente localidad de trabajadores, proveedores, consumidores 0 usuarios de las mismas, privilegiando al ser humano como sujeto y fin de su actividad, orientada al buen vivir, en armonía con la naturaleza, por sobre el lucro y la acumulación de capital (Ley de la EPS, artículo 1, Capítulo 1, pág. 1)

La EPS tiene su origen en las formas de organización de los sectores populares y de sus iniciativas y emprendimientos frente a la lógica capitalista excluyente y de acumulación. Su objetivo esencial es el ser humano y la satisfacción de sus necesidades, así como la prestación de servicios a los miembros del territorio o de la comunidad y el reconocimiento de diferentes formas de organización de la sociedad para la producción, en las que la sociedad de las personas está por encima de la sociedad de capitales.

En este sentido se destaca que Ecuador reconoce en su artículo 283 de la Constitución de la República (Asamblea Nacional del Ecuador, 2008) que "el sistema económico es social y solidario", y se especifican los siguientes objetivos:

1. Mejorar la calidad y esperanza de vida, y aumentar las capacidades y potencialidades de la población en el marco de los principios y derechos que establece la Constitución.

2. Construir un sistema económico justo, democrático, productivo, solidario y sostenible basado en la distribución igualitaria de los beneficios del desarrollo, de los medios de producción y en la generación de trabajo digno y estable. Así como en muchos países de la región, la posibilidad de superar la pobreza pasa por mejorar las capacidades sistémicas territoriales, asumiendo la población la gestión de su propio desarrollo, a través de la capitalización y canalización de recursos económicos orientados a financiar la generación de bienes y servicios, como requisito para propiciar mejores condiciones socio-comunitarias y económicas para alcanzar una mejor forma de vivir. 
3. Impulsar las Finanzas Populares y Solidarias (FPS) en el país, lo que ha sido de gran importancia para democratizar los servicios financieros y potenciar el desarrollo endógeno, desde abajo, lo que exige promover la participación e interacción efectiva del Estado y la sociedad civil.

"La Economía Popular y Solidaria se ha convertido en Ecuador en una vía fundamental para lograr elevar la producción, el empleo, los ingresos y el desarrollo de las organizaciones del sector comunitario" (Auquilla, 2014, p.9).

Desde el sistema económico social y solidario del Ecuador es necesario asumir las Finanzas Populares y Solidarias como parte del nuevo Sistema Económico, Social y Solidario en el que se diseña una nueva arquitectura financiera al servicio de la sociedad.

Por lo que hay que dejar de hablar y pensar en Microfinanzas para asumir la categoría Finanzas Populares y Solidarias, dentro de la cual, el alcance, la profundidad y la calidad de los servicios financieros orientados al desarrollo local y territorial son de trascendental importancia (Cardoso, 2014, p.5).

Se conciben las Finanzas Populares y Solidarias como:

El conjunto de ideas, esfuerzos, capacidades, apoyos, normas, programas, instrumentos, recursos y estructuras, que actúan en cada situación geográfica definida y limitada (recinto, parroquia, barrio, urbano, suburbano y rural), para que la población organice el mercado financiero del ahorro, del crédito y de los servicios financieros en su propio beneficio y en pos del desarrollo de toda la comunidad, abiertos al intercambio de productos y servicios financieros con otras localidades, en perspectiva de construir un nuevo sistema de flujos financieros, que tengan al ser humano como centro del desarrollo económico y social.

Las FPS permiten distinguir a aquellas instituciones que brindan un servicio con fines comerciales, de aquellas que nacen con una visión crítica de los procesos económicos y buscan generar oportunidades del desarrollo desde las comunidades locales como lo son las OSFPS integradas en un nuevo sistema económico. 
Revista Científica Arbitrada de Investigación en Comunicación, Marketing y Empresa REICOMUNICAR. Vol. 4, Núm. 7 (ene - jun 2021) ISSN: 2737-6354.

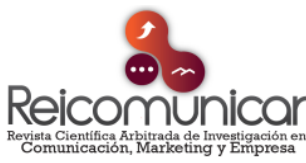

Consideraciones teóricas sobre la gestión de las Microfinanzas con un enfoque de Finanzas

Populares y Solidarias

De esa forma, mientras las instituciones microfinancieras ven en los emprendedores sólo una salida laboral desde el individuo, las FPS aspiran a convertirlas, junto al sistema de Economía Popular y Solidaria, en semillas de una economía más solidaria y humana para la reproducción de las condiciones de la vida humana (Verduga, 2016).

Actualmente, se evidencia el surgimiento de iniciativas de ahorro y crédito que, en su intervención como actores populares en el mercado financiero, no garantizan el pleno y real desarrollo de las FPS, pues se requiere que los flujos económicos de estas organizaciones se entrecrucen mediante la prestación de diversos servicios. Es entonces, cuando las organizaciones populares comprenden y asumen un rol protagónico y articulador de la intermediación y prestación de servicios financieros entre sí.

Cuando estos flujos se entrelacen será el momento de hablar de la plena y real construcción de una nueva arquitectura y tejido financiero alternativo y solidario.

Para garantizar la sostenibilidad financiera y social de los emprendimientos de la EPS se requiere la integración de todos los actores: sujetos sociales públicos, privados, populares y solidarios, así como de la participación del Estado, el cual debe apoyar para su desarrollo.

Se necesita, por tanto, que desde el Estado y las políticas públicas se reconozcan estas instancias que componen el quehacer de las FPS, que organizan su gestión de intermediación y prestación de servicios financieros, guiados no por la lógica capitalista de acumulación y extracción de recursos, sino por el servicio hacia el desarrollo local.

Esta perspectiva implica también, la búsqueda de rentabilidad, pero no a costa de la descapitalización de los destinatarios de los servicios financieros, ni provocando el impacto social y ambiental con los emprendimientos de la EPS.

En consecuencia, se fomenta e impulsa el desarrollo local, puesto que se constituyen en agentes que aportan al devenir social, económico y productivo de estas localidades. Ello supone la comprensión amplia del potencial que tienen las comunidades rurales y urbanas populares para mediar en el mercado de flujos locales y nacionales; significa entender la intervención financiera como un 
instrumento para el desarrollo con equidad, a través de formas asociativas y no como un medio de concentración de riqueza, por una parte, mientras se acumula pobreza en sectores excluidos.

Las OSFPS que forman parte del Sector Financiero Popular y Solidario (SFPS) captan el ahorro local, lo reinvierten vía crédito en la producción, y desarrollan servicios financieros complementarios, lo cual puede contribuir a articular estas iniciativas en un espacio alternativo y solidario que tiene las siguientes particularidades:

- La consideración acerca de que las organizaciones del sistema de Finanzas Populares y Solidarias son organizaciones populares con gran potencial económico significó rupturas de los enfoques tradicionales de profundización financiera y bancarización, desarrollando nuevos paradigmas de finanzas, bajo principios sociales y solidarios, lo que lleva a proponer la política pública de rectoría, regulación y control, apropiada a la realidad del sector FPS, que tenga en cuenta aspectos de desempeño social y prudencia financiera.

- La implementación de productos y servicios financieros, de acuerdo a la demanda y condiciones particulares de los emprendimientos de la Economía Popular y Economía Popular y Solidaria, así como la articulación con las políticas públicas y la institucionalidad del SFPS-EPS.

- La formulación e innovación de los instrumentos de política pública y servicios financieros orientados hacia la inserción de las formas populares de ahorro y crédito al servicio de las iniciativas emprendedoras de la EP/EPS.

Para cubrir las limitaciones de las microfinanzas en el territorio se deben acoger favorablemente a los potenciales objetivos de las Finanzas Populares que son: combatir la usura; promover la inversión productiva en la comunidad y crear opciones laborales bajo responsabilidad familiar o comunitaria.

Para ello las estructuras financieras de las FPS en la zona objeto de estudio deberían: 
Revista Científica Arbitrada de Investigación en Comunicación, Marketing y Empresa

- Estimular el ahorro, bajar el costo del dinero, financiar los proyectos para el desarrollo del territorio, producción, comercio, empleo, servicios, innovación y desarrollo;

- Vincular la educación superior e inversión en l+D+l (Investigación + Desarrollo+ Innovación Tecnológica),

- Consolidar la conectividad con el espacio virtual y las telecomunicaciones en el territorio de actuación, incluir y no excluir de acuerdo al nivel de disponibilidad de recursos y garantías que exige el sistema bancario tradicional para poder tener el derecho al financiamiento bancario,

- Agregar valor a la acción financiera, productiva en aspectos de organización, formación profesional, equidad, respeto del medio ambiente, participación democrática, entre otros.

- Descubrir la vocación y el sentido del desarrollo territorial a escala local y establecer redes de cooperación parroquial, cantonal, provincial, regional y nacional.

Como se puede apreciar, en el contexto del sector financiero ecuatoriano las Microfinanzas tienen lugar en un ámbito de informalidad en el que se llevan a cabo emprendimientos de sobrevivencia, son formas no asociativas que desarrollan procesos irregulares, mientras que las FPS están asociadas, generan emprendimientos en el territorio y se rigen por la ley de las OFPS.

\section{METODOLOGÍA}

La investigación llevada a cabo se origina a partir del siguiente problema científico: ¿cómo transformar las Microfinanzas para superar sus limitaciones actuales y propiciar la inclusión financiera de los sectores vulnerables del Ecuador?

El objeto de la investigación lo constituyen las Microfinanzas y el campo de acción, el proceso de su transformación en Finanzas Populares y Solidarias en Portoviejo, Ecuador. 
Se emplearon métodos del nivel teórico tales como: el histórico-lógico para analizar la evolución de las Microfinanzas en los escenarios estudiados; el analítico-sintético para estudiar los referentes teórico-metodológicos que sustentan el objeto de estudio, así como para llegar a las conclusiones derivadas del procesamiento de la información acerca del mismo, y el inductivo-deductivo para determinar las particularidades de las Microfinanzas y de las Finanzas Populares y Solidarias, a partir de la sistematización de los referentes teóricos consultados.

\section{RESULTADOS}

Como se puede apreciar, en el contexto del sector financiero ecuatoriano las Microfinanzas tienen lugar en un ámbito de informalidad en el que se llevan a cabo emprendimientos de sobrevivencia, son formas no asociativas que desarrollan procesos irregulares y no han favorecido la reducción de la pobreza, ni han fomentado el desarrollo.

Por su parte, las Finanzas Populares y Solidarias generan emprendimientos en el territorio, ofrecen un sistema de garantías colectivas y solidarias, promueven el desarrollo local bajo la lógica del trabajo asociado, y con el apoyo de políticas públicas, favorecen la innovación y la tecnología.

\section{DISCUSIÓN}

El análisis realizado acerca de las Microfinanzas hizo posible profundizar en la evolución de las mismas durante su desarrollo histórico, así como identificar las contradicciones y limitaciones que poseen, las cuales justifican su transformación en aras de favorecer la inclusión financiera de los sectores vulnerables del Ecuador.

Las indiscutibles ventajas que brindan las Finanzas Populares y Solidarias permiten aseverar la factibilidad de trabajar por lograr la gestión de las Microfinanzas con un enfoque de Finanzas Populares y Solidarias. 


\section{CONCLUSIONES}

La valoración crítica de lo antes expuesto se dirige, en primer lugar, a reconocer el papel del microcrédito y las Microfinanzas de acuerdo al escenario en que se desenvuelven; el primero de manera más específica, exclusivamente en la colocación de un préstamo pequeño a corto plazo, con un interés acorde a las tasas vigentes, y las otras que abren el espectro local, siendo más inclusivas dentro de un territorio de subsistencia y marginalidad, brindando además, una gama de servicios para satisfacer las diferentes demandas de la comunidad.

La Economía Popular y Solidaria, reconocida por la Constitución del Ecuador del 2008 como un sistema económico que coexiste con el público y el privado, ha comprobado su capacidad de construir una alternativa a la economía neo-liberal actualmente dominante. Dentro de este sistema económico, la EPS constituye una respuesta concreta a las necesidades y aspiraciones de las personas que participan de ella. En el marco de la EPS, las Finanzas Populares y Solidarias revisten especial significación al constituir un mecanismo de organización y participación de los actores y sujetos sociales de la economía popular en el sistema financiero, dentro de los cuales, los sectores excluidos constituyen una parte importante.

\section{REFERENCIAS}

Ashraf, N., Gine, X. \& Karlan, D. (2008). Encontrar mercados perdidos (y un epílogo perturbador): evidencia de una intervención de comercialización y adopción de cultivos de exportación en Kenia. American Journal of Agricultural Economics, 91 (4), 973-990

Askunze, C. (2007). Economía Solidaria. REAS Euskadi- Red de Economía Alternativa y Solidaria

Auquilla, L. \& Del Castillo, L. (2013). La Economía Popular y Solidaria inclusiva en las localidades de la Junta parroquial rural San José. Revista Economía y Desarrollo, julio a diciembre (2), 170-182. ISSN: 0252-8584.

Banco Central del Ecuador (2016). Recuperado de http://www.bce.fin.ec

Banerjee, A., Duflo, E., Glennester, R., Kinnan, C. (2009). The miracle of microfinance? Evidence from a randomized evaluation. 
Cárdenas Félix, C J; Hirsch, J; Lara Gómez, G; (2015). Estructuras contractuales en el Sector de las Finanzas Populares en el Municipio de Querétaro en México. CIRIEC España. Revista de Economía Pública, Social y Cooperativa, 84, 133-162. ISSN: 0213-8093

CEPAL (2017). Perspectivas de la agricultura y el desarrollo rural en las

CEPAL (2018).

Constitución de la República del Ecuador. (2008). Registro Oficial No. 449, Artículo 283, Quito.

Copestake, J., Bhalotra, S.\& Johnson, S. (2001), Evaluación del impacto del microcrédito: un estudio de caso de Zambia, Journal of Development Studies, 37, (4), 81-100,

Coraggio, J. (2011). Economía Social y Solidaria. El trabajo antes que el capital. Ediciones Abya-Yala, Quito, Ecuador.

Duvendack, M. et al. (2011). ¿Cuál es la evidencia del impacto de las microfinanzas en el bienestar de las personas pobres? Centro EPPI. ISBN: 9781907345197

Garayalde, M. (2014). Microfinanzas: evolución histórica de sus instituciones y de su impacto en el desarrollo. REVESCO. Revista De Estudios Cooperativos, 116 , 130-159. https://doi.org/10.5209/rev_REVE.2014.v116.46570

Hernández, R. (2014). El microcrédito para la microempresa. Una aproximación a experiencias de microcrédito en América Latina. Proyecto Local Barcelona Solidaria, Ayuntamiento de Barcelona Cooperación Española.

Husain, Z., Mukherjee, D. \& Dutta, M. (2014). Self Help Groups and empowerment of women: Self-selection or actual benefits? Journal of International Development. 26 (4). DOI: 10.1002/jid.2815.

Junta de Política y Regulación Monetaria y Financiera (2016). Resolución No. 209-2016-F. Norma para la calificación de activos de riesgo y constitución de provisiones por parte de las entidades de los sectores financieros público y privado bajo el control de la Superintendencia de Bancos.

Junta de Política y Regulación Monetaria y Financiera (2017). Resolución 3912017-F. Inclusión en la Codificación de Resoluciones Monetarias, Financieras, de Valores y Seguros de la Junta de Política y Regulación Monetaria y Financiera, capítulo XLIII "Programa de Crédito para las entidades del Sector Financiero Público". 
Revista Científica Arbitrada de Investigación en Comunicación, Marketing y Empresa REICOMUNICAR. Vol. 4, Núm. 7 (ene - jun 2021) ISSN: 2737-6354.

Consideraciones teóricas sobre la gestión de las Microfinanzas con un enfoque de Finanzas Populares y Solidarias

Junta de Política y Regulación Monetaria y Financiera (2018). Resolución No. 437-2018-F. Modificación de las tasas de interés activas efectivas máximas.

Karnani, A. (2007). El empleo, no microcrédito, es la solución. Ross School of Business Paper No. 1065. Recuperado de SSRN: https://ssrn.com/abstract=962941 o http://dx.doi.org/10.2139/ssrn.962941

Ledgerwood, J. (2000). Microfinance Handbook: An Institutional and Financial Perspective. Washington DC: The World Bank, 2000, 1.

LOEPS (2011a). Registro Oficial No. 444, Artículo 1, Quito.

Morduch, J. (2000). El cisma de las microfinanzas. Desarrollo Mundial, 28 (4).

Nanor, M. (2008). Microfinance and its Impact on Selected Districts in Eastern Region of Ghana. College of Art and Social Sciences, Kumasi: Kwame Nkrumah University of Science and Technology.

OIT (2005). Características y funciones de la Empresa Cooperativa. INTERCOOP, Buenos Aires.

Paucar, M. (2013). Las Microfinanzas en el Ecuador, Microcréditos como factor fundamental para el desarrollo de las PYMES. Recuperado de http://www.sistemasune-sum.com/BlogUNESUM/?p=171

Pérez, E., Titelman, D. \& Caldentey, C. (2018). A Brief Note on Innovative Finance for Development Mechanisms. ECLAC, Financing for Development Division November, 2011. Santiago, Chile.

Sarria, A. (2010). Economía Popular. CIRIEC-España. Revista de Economía Pública, Social y Cooperativa. Recuperado de: http://uv.es/reciriec

Udry C. \& Aryeetey E. (2010.) Creating Property Rights: Land Banks in Ghana, American Economic Review Papers and Proceedings, 100 (2), 130-134.

Van Rooyen, C., Stewart, R. \& De Wet, T. (2012). El impacto de las microfinanzas en el África subsahariana: una revisión sistemática de la evidencia. Revista Desarrollo Mundial, 40 (11), 2249-2262. Recuperado de http://www.sciencedirect.com/science/article/pii/S0305750X12000496

Verduga, A. (2016). Las Finanzas Populares y Solidarias como alternativa ante la banca tradicional excluyente, 23.

Yunus, M. (2008). Banquero de los Pobres. El Microcrédito y la Batalla Contr. PAIDÓS.

Recuperado

de https://www.boutiquedellibro.com.ar/Papel/9789501264371/Banquero+D e+Los+Pobres++El++Microcreditos+Y+La+Batalla+Cont 